\title{
Milk and Blood Pharmacokinetics of Tylosin and Tilmicosin following Parenteral Administrations to Cows
}

\author{
Tulay Avci ${ }^{1}$ and Muammer Elmas ${ }^{2}$ \\ ${ }^{1}$ Department of Toxicology, Veterinary Control Institute, 42080 Konya, Turkey \\ ${ }^{2}$ Department of Pharmacology and Toxicology, Faculty of Veterinary Medicine, University of Selcuk, 42003 Konya, Turkey \\ Correspondence should be addressed to Tulay Avci; tulay_avc@hotmail.com
}

Received 11 June 2014; Accepted 10 July 2014; Published 6 August 2014

Academic Editor: Halis Oguz

Copyright (c) 2014 T. Avci and M. Elmas. This is an open access article distributed under the Creative Commons Attribution License, which permits unrestricted use, distribution, and reproduction in any medium, provided the original work is properly cited.

\begin{abstract}
The aim of this study is to determine the pharmacokinetics of tylosin and tilmicosin in serum and milk in healthy Holstein breed cows $(n=12)$ and reevaluate the amount of residue in milk. Following the intramuscular administration of tylosin, the maximum concentrations $\left(C_{\max }\right)$ in serum and milk were found to be $1.30 \pm 0.24$ and $4.55 \pm 0.23 \mu \mathrm{g} / \mathrm{mL}$, the time required to reach the peak concentration $\left(t_{\max }\right)$ was found to be 2 nd and 4 th $\mathrm{h}$, and elimination half-lives $\left(t_{1 / 2 \beta}\right)$ were found to be $20.46 \pm 2.08$ and $26.36 \pm 5.55 \mathrm{~h}$, respectively. Following the subcutaneous administration of tilmicosin, the $C_{\max }$ in serum and milk were found to be $0.86 \pm 0.20$ and $20.16 \pm 1.13 \mu \mathrm{g} / \mathrm{mL}$, the $t_{\max }$ was found to be 1 st and $8 \mathrm{th} \mathrm{h}$, and the $t_{1 / 2 \beta}$ were found to be $29.94 \pm 6.65$ and $43.02 \pm 5.18 \mathrm{~h}$, respectively. $\mathrm{AUC}_{\text {milk }} / \mathrm{AUC}_{\text {serum }}$ and $C_{\text {max-milk }} / C_{\text {max-serum }}$ rates, which are indicators for determining the rate of drugs that pass into milk, were, respectively, calculated as $5.01 \pm 0.72$ and $3.61 \pm 0.69$ for tylosin and $23.91 \pm 6.38$ and $20.16 \pm 1.13$ for tilmicosin. In conclusion, it may be stated that milk concentration of tylosin after parenteral administration is higher than expected like tilmicosin and needs more withdrawal period for milk than reported.
\end{abstract}

\section{Introduction}

Tylosin (tylosin A) was first derived in 1960 by Mac Fuire from Streptomyces fradiae cultures. Tylosin exists in several forms, including the minor constituents desmycosin (tylosin B), macrocin (tylosin C), and relomycin (tylosin D), and is known for its metabolites lactenocin (tylosin L), 5O-mycaminosyltylonolide (OMT), and demycinosyl-tylosin (DMT). Tylosin exerts bacteriostatic effect on Mycoplasma species and Gram-positive bacteria. It is well absorbed when administered by oral and parenteral routes and is eliminated from the body slowly. Tylosin binds to serum and milk proteins at rates of $25-47 \%$ and $15 \%$, respectively $[1,2]$. In most animal species, the half-life $\left(t_{1 / 2}\right)$ of tylosin is $3-4 \mathrm{~h}$ and the volume of distribution $\left(V_{d}\right)$ ranges between 1 and $7 \mathrm{~L} / \mathrm{kg}$. Tylosin passes readily into milk and its concentrations in milk may be five times higher than its plasma concentrations. Tylosin does not undergo major modification in the body and is excreted mainly in bile and milk and partly in urine [3]. The unmodified form of tylosin passes into milk and eggs.
As reported by the European Medicines Evaluation Agency (EMEA), the maximum residue limit (MRL) established for tylosin in cow's milk is $50 \mu \mathrm{g} / \mathrm{kg}$. The withdrawal periods for meat and milk, in the event of the parenteral administration of tylosin to cattle, sheep, and goats, are 28 days and 8 milkings, respectively.

Tilmicosin is a 16 -membered ring, semisynthetic macrolide antibiotic, with a chemical structure of 20-deoxo-20(3,5-dimethylpiperidin-1-yl) desmycosin [4]. This drug is used in both cattle [5] and calves [6], for prophylactic and therapeutic purposes, against pneumonia caused by Pasteurella multocida, Pasteurella haemolytica, Actinobacillus pleuropneumonia, and Mycoplasma species [7]. Tilmicosin is preferably administered by subcutaneous (SC) route, but it may also be administered by intramuscular (IM) route. When administered subcutaneously or intramuscularly, tilcomisin reaches its peak plasma concentration (ranging between 0.8 and $1.7 \mu \mathrm{g} / \mathrm{mL}$ when administered at normal doses) within approximately $60 \mathrm{~min}$. Tilmicosin accumulates particularly in the lungs, and its pulmonary concentration 
may be 50 to 60 times higher than its plasma concentration. It is converted mainly into desmethyl tilmicosin in the body and is excreted mainly in the bile, either unmetabolized or in the form of its metabolites. Tilmicosin may also be eliminated in the urine $[3,8]$. As reported by the EMEA, the MRL established for tylosin in cow's milk is $50 \mu \mathrm{g} / \mathrm{kg}$. In cattle, when administered parenterally, the withdrawal period for meat (applied prior to slaughter) is 60 days.

This study was aimed at the measurement of the levels of tylosin and tilmicosin, which are both macrolide antibiotics, in positive serum and milk samples obtained by the administration of $17.5 \mathrm{mg} / \mathrm{kg}$ bw of tylosin by IM route and $10 \mathrm{mg} / \mathrm{kg}$ bw of tilmicosin by SC route to clinically healthy Holstein cattle, following the method validation of highpressure liquid chromatography-UV (HPLC-UV). It was also aimed at determining certain pharmacokinetic parameters and at assessing antibiotic residues in milk.

\section{Materials and Methods}

2.1. Experimental Animals. The study was carried out on 12 healthy dairy cattle (Holstein, 350-400 kg, 3-4 years, mean daily milk yield of $18-22 \mathrm{~kg}$ ), the milk somatic cell counts of which were determined to be $\leq 500.000$ by microscopy. To prevent the administration of any drugs, the animals were maintained under the same management and feeding conditions for 1 month. This study was approved by the Ethics Board of Selcuk University, Faculty of Veterinary Medicine (no. 2007/064).

2.2. Drug Administration and Sampling. The animals were randomly allocated to 2 groups, each composed of 6 cattle. The first group was administered with $10 \mathrm{mg} / \mathrm{kg}$ bw of tilmicosin (Micotil 300, injectable) into the dorsolateral region of the neck by SC route, while the second group was administered with $17.5 \mathrm{mg} / \mathrm{kg}$ bw of tylosin (Tylan 200, injectable) into the dorsolateral region of the neck by IM route.

The antibiotics were administered prior to the morning milking, between 06.00 and 07.30 a.m. Blood samples $(10 \mathrm{~mL})$ were collected from the jugular vein into sterile vacutainers (in glass centrifuge tubes) prior to antibiotic administration (0) and 10, 20, and $40 \mathrm{~min}$ and 1, 2, 3, 4, 6, 8, 10, 12, 24, 48, 72, and $96 \mathrm{~h}$ after administration. Within $1 \mathrm{~h}$ after being collected, the blood samples were centrifuged at $3500 \mathrm{rpm}$ for $15 \mathrm{~min}$. The serum samples obtained were stored at $-20^{\circ} \mathrm{C}$ until being analysed.

At each sampling interval, prior to antibiotic administration (0) and at $0.5,1,2,4,8,12,24,48,72,96$, and $120 \mathrm{~h}$ after administration, the udders were milked out by hand. Milk samples $(100 \mathrm{~mL})$ were collected into sterile tubes, transferred to the laboratory under cold chain conditions, and stored at $-20^{\circ} \mathrm{C}$ until being analysed.

The serum concentrations of tilmicosin and tylosin were measured using HPLC-UV and the modified methods of Moran et al. [9] and García-Mayor et al. [10].

The milk concentrations of tilmicosin and tylosin were ascertained by means of HPLC-UV and using the modified methods of Dudrikova et al. [11], Stobba-Wiley and Readnour
[7], and García-Mayor et al. [10]. Specificity and selectivity, linearity and measuring range, recovery and accuracy, and sensitivity limit of detection (LOD) and limit of quantification (LOQ), and precision were used as performance criteria for method validation [3].

2.3. Pharmacokinetic Calculations. The serum/milk concentration-time curves of tylosin and tilmicosin were drawn for each animal with the aid of the WinNonlin [12] software. The pharmacokinetic model most appropriate for the interpretation of the parameters pertaining to each of the antibiotics was determined, based on the direct inspection of the individual serum concentration-time curves and the Akaike information criteria (AIC) [13]. In all of the animals, the pharmacokinetic parameters related to the serum concentrations of tylosin and tilmicosin were found to be most consistent with the two-compartment open model. The pharmacokinetic parameters obtained for milk were calculated using a noncompartmental model analysis.

The maximum concentrations of tylosin and tilmicosin $\left(C_{\max }\right)$ and the time periods within which the maximum concentrations were reached $\left(t_{\max }\right)$ were ascertained based on the observation of the serum/milk concentration-time curves of each animal. For each of the two antibiotics, the $C_{\max }$ values were given in mean $\pm \mathrm{SD}$ and the $t_{\max }$ values were presented as means.

2.4. Statistical Analysis. All values were presented in mean \pm $\mathrm{SD}$. For the time parameters $\left(t_{1 / 2 \mathrm{ab}}, t_{1 / 2 \alpha}\right.$, and $\left.t_{1 / 2 \beta}\right)$, the harmonic mean \pm SD was calculated. For both antibiotics, the statistical differences between the serum and milk concentrations, $C_{\max }$, and AUC parameters were evaluated using the SPSS 15.0 statistical package programme and paired-samples t-test. The statistical differences for $t_{1 / 2 \beta}$ were assessed with the nonparametric Wilcoxon signed-rank test. The withinday and between-day differences of the method for tylosin and tilmicosin were reflected in standard deviations and percentage variation coefficients. A descriptive statistical assessment was made, based on the concentrations determined in repeated analyses, and mean \pm SD and percentage (\%) variation coefficients were calculated. The confidence interval was $95 \%$ in all analyses. In the statistical analyses, the level of significance was accepted as $P<0.05$.

\section{Results}

Milk/serum concentration-time curves were drawn following the intramuscular administration of a single dose $(17.5 \mathrm{mg} / \mathrm{kg}$ bw) of tylosin (Figure 1). Statistical differences were determined to exist between the milk and serum concentrations of tylosin for the same sampling intervals $(1,2,4,8,12,24$, and $48 \mathrm{~h}$ after administration $)(P<0.05)$.

Milk/serum concentration-time curves were drawn following the subcutaneous administration of a single dose $(10 \mathrm{mg} / \mathrm{kg} \mathrm{bw})$ of tilmicosin (Figure 2).

It was determined that statistically significant differences existed between the milk and serum concentrations of 


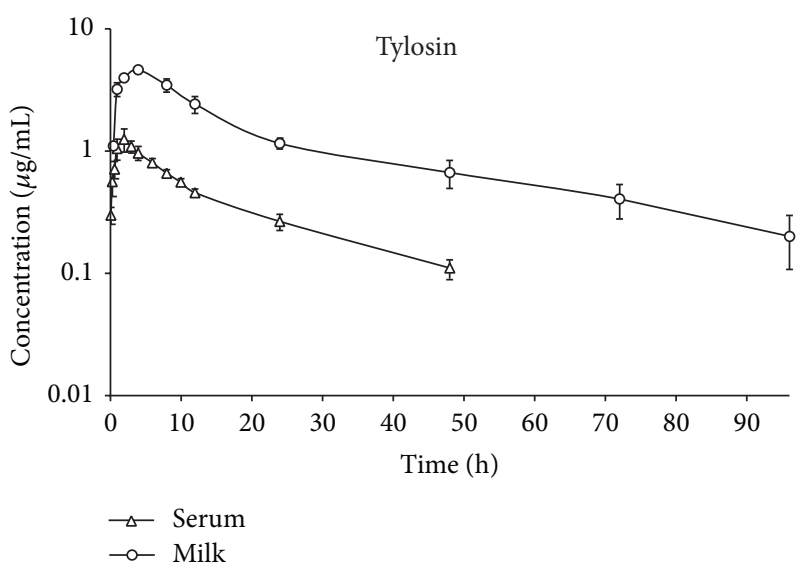

FIGURE 1: Semilogarithmic milk and serum concentration-time profiles of tylosin after the intramuscular administration of a single dose of $17.5 \mathrm{mg} / \mathrm{kg}(n=6)$.

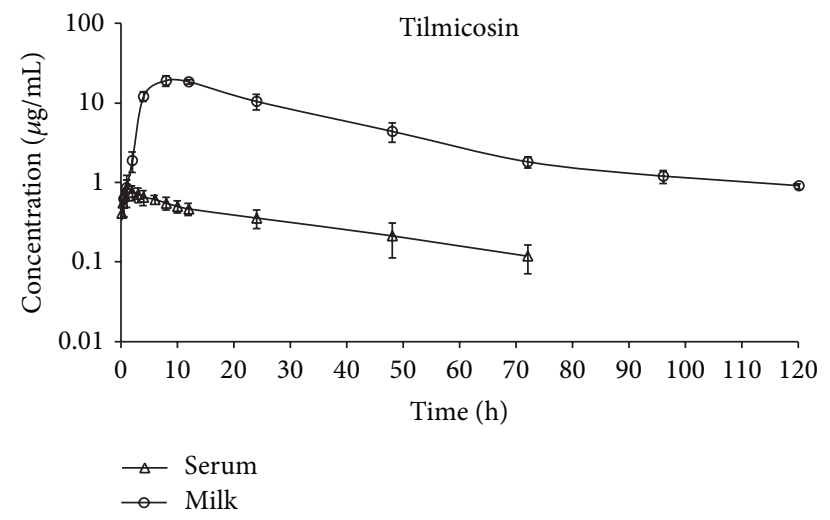

FIGURE 2: Semilogarithmic milk and serum concentration-time profiles of tilmicosin after the subcutaneous administration of a single dose of $10 \mathrm{mg} / \mathrm{kg}(n=6)$.

tilmicosin measured at 2, 4, 8, 12, 24, 48, 72, and $96 \mathrm{~h}$ after administration $(P<0.05)$.

Pharmacokinetic parameters for tylosin and tilmicosin in serum and milk were calculated in Holstein cattle using a twocompartment open model and a noncompartmental analysis model (Table 1).

\section{Discussion}

Following IM administration, tylosin was detected from the 10 th min up to $48 \mathrm{~h}$ after administration in the serum and from the 30 th min up to $96 \mathrm{~h}$ after administration in the milk. These results were found to be in parallel with those reported in previous research carried out in cattle $[2,14,15]$. Following SC administration, tilmicosin was detected from the 10th min up to $72 \mathrm{~h}$ after administration in the serum and from the 30 th min up to $120 \mathrm{~h}$ after administration in the milk. These results were similar to those previously reported in cattle [16] and goats [17]. It was ascertained that, following the IM administration of tylosin and the SC administration of tilmicosin, the serum concentration-time curves of both antibiotics were consistent with the two-compartment open model (Figures 1 and 2). Similarly, while the two-compartment open model has been used for calculations in previous research [16-21], it has been observed that, in studies in which a consistency analysis (based on direct observation and AIC) was not performed $[8,22-24]$, the noncompartmental model was used.

In the present study, following IM administration, tylosin was determined to have reached its serum maximum concentration $(1.30 \pm 0.24 \mu \mathrm{g} / \mathrm{mL})$ by the $2 \mathrm{nd} \mathrm{h}$ following administration (Table 1). Similar results have been reported in a previous study in cattle [2].

The elimination half-life $\left(t_{1 / 2 \beta}\right)$ of tylosin in serum was determined to be $20.46 \pm 2.08 \mathrm{~h}$ (Table 1 ). This is longer than the values previously reported for other animal species (calf $2.24 \mathrm{~h}$, buffalo $2.40 \mathrm{~h}$, camel $2.73-3.71 \mathrm{~h}$, pig 3.01-3.88 h, sheep $2.3-6 \mathrm{~h}$, and goat $5 \mathrm{~h})[15,21,24,25]$. The variability of the elimination half-lives of this antibiotic in different animal species is attributed to the anatomical and physiological differences between these species as well as to the differences in the formulation of the drug [25]. The long elimination halflife of tylosin in cattle demonstrates that its penetration level is low and its retention period in the tissues is long. These results are in compliance with those reported in previous research in cattle $[2,15]$, goats [20, 21], and sheep [25].

In the present study, following SC administration, tilmicosin was determined to have reached its serum peak concentration $(0.86 \pm 0.20 \mu \mathrm{g} / \mathrm{mL})$ by the 1 st h following administration (Table 1). Similar to the results obtained in the present study, the serum peak concentrations of tilmicosin in sheep, cattle, calves, goats, and chickens were reported as 0.822 , $0.873,1.10,1.56$, and $1.28-2.12 \mu \mathrm{g} / \mathrm{mL}$, respectively, whilst the time period required for reaching the serum peak concentration was reported as $3.9,0.5,1,6.39$, and $4.66-5.82 \mathrm{~h}$, respectively, in the same animal species $[6,16,17,23]$.

In the present study, the serum elimination half-life $\left(t_{1 / 2 \beta}\right)$ of tilmicosin was ascertained to be $29.94 \pm 6.65 \mathrm{~h}$ (Table 1 ) and this result was observed to comply with previous literature reports (cattle $29 \mathrm{~h}$, goats $29.3 \mathrm{~h}$, sheep $33 \mathrm{~h}$, chickens $30.18-$ $45.0 \mathrm{~h}$, and foals $18.4 \pm 10.7 \mathrm{~h})[16,17,22,23,26]$. Despite the physiological and morphological differences of chickens from other animal species, the pharmacokinetic parameters determined for tilmicosin in chickens display similarity to those determined in ruminants. This could be attributed to the fact that a larger part of this drug is not metabolized [16].

After administrations, tylosin and tilomicosin were first detected in milk at the first sampling interval. At all sampling intervals, the milk concentrations of the antibiotics were significantly higher than their serum concentrations $(P<0.05$, Figures 1 and 2 ). These results complied with those previously reported for tylosin [1, 2, 20, 25] and tilmicosin [17]. The high concentrations of both antibiotics reached in the milk following extravenous administration could be explained by nonionic passive diffusion [2].

The $\mathrm{AUC}_{\text {milk }} / \mathrm{AUC}_{\text {serum }}$ and $C_{\text {max-milk }} / C_{\text {max-serum }}$ ratios of both of the antibiotics are indicators of the passage of them into the mammary glands following systemic administration in lactating dairy cattle [25]. 
TABle 1: Pharmacokinetic parameters of tylosin $(17.5 \mathrm{mg} / \mathrm{kg}, \mathrm{IM})$ and tilmicosin $(10 \mathrm{mg} / \mathrm{kg}, \mathrm{SC})$ in Holstein cows $(n=6)$ after a single parenteral administration.

\begin{tabular}{|c|c|c|c|c|}
\hline \multirow{2}{*}{ Parameters } & \multicolumn{2}{|c|}{ Tylosin $($ mean \pm SD) } & \multicolumn{2}{|c|}{ Tilmicosin $($ mean \pm SD $)$} \\
\hline & Serum & Milk & Serum & Milk \\
\hline$C_{\max }(\mu \mathrm{g} / \mathrm{mL})$ & $1.30 \pm 0.24$ & $4.55 \pm 0.23^{*}$ & $0.86 \pm 0.20$ & $20.16 \pm 1.13^{*}$ \\
\hline$t_{\max }(\mathrm{h})$ & 2 & 4 & 1 & 8 \\
\hline $\operatorname{AUC}(\mu \mathrm{g} \cdot \mathrm{h} / \mathrm{mL})$ & $20.95 \pm 1.73$ & $104.29 \pm 12.63^{*}$ & $28.42 \pm 8.68$ & $639.09 \pm 65.33^{*}$ \\
\hline$t_{1 / 2 \mathrm{ab}}(\mathrm{HO})(\mathrm{h})$ & $0.54 \pm 0.31$ & - & $0.21 \pm 0.04$ & - \\
\hline$\alpha\left(\mathrm{h}^{-1}\right)$ & $0.26 \pm 0.19$ & - & $0.26 \pm 0.09$ & - \\
\hline$\beta\left(\mathrm{h}^{-1}\right)$ & $0.03 \pm 0.003$ & - & $0.02 \pm 0.005$ & - \\
\hline$t_{1 / 2 \alpha}(\mathrm{HO})(\mathrm{h})$ & $2.63 \pm 2.50$ & - & $2.68 \pm 1.10$ & - \\
\hline$t_{1 / 2 \beta}(\mathrm{HO})(\mathrm{h})$ & $20.46 \pm 2.08$ & $26.36 \pm 5.55^{*}$ & $29.94 \pm 6.65$ & $43.02 \pm 5.18^{*}$ \\
\hline$V_{d}(\mathrm{~L} / \mathrm{kg})$ & $20 \pm 0.9$ & - & $15.56 \pm 2.95$ & - \\
\hline$K_{01}\left(\mathrm{~h}^{-1}\right)$ & $1.28 \pm 0.57$ & - & $3.14 \pm 0.54$ & - \\
\hline$K_{12}\left(\mathrm{~h}^{-1}\right)$ & $0.08 \pm 0.07$ & - & $0.07 \pm 0.04$ & - \\
\hline$K_{21}\left(\mathrm{~h}^{-1}\right)$ & $0.10 \pm 0.05$ & - & $0.18 \pm 0.04$ & - \\
\hline$C_{\text {max-milk }} / C_{\text {max-serum }}$ & \multicolumn{2}{|c|}{$3.61 \pm 0.69$} & \multicolumn{2}{|c|}{$20.16 \pm 1.13$} \\
\hline $\mathrm{AUC}_{\text {milk }} / \mathrm{AUC}_{\text {serum }}$ & \multicolumn{2}{|c|}{$5.01 \pm 0.72$} & \multicolumn{2}{|c|}{$23.91 \pm 6.38$} \\
\hline
\end{tabular}

${ }^{*}$ Values shown in the same row are statistically significant $(P<0.05)$.

$C_{\max }$ : maximum concentration; $t_{\max }$ : time to peak concentration; AUC: area under the curve from zero to infinity by the trapezoidal integral; $t_{1 / 2 a b}$ : absorption half-life; $\alpha$; distribution rate constant; $\beta$ : elimination rate constant; $t_{1 / 2 \alpha}$ : distribution half-life; $t_{1 / 2 \beta}$ : elimination half-life; $V_{d}$; volume of distribution; $K_{01}$ : firstorder elimination rate constant; $K_{12}$ and $K_{21}$ : first-order rate constants for drug distribution between the central and peripheral compartments; HO: harmonic mean, SD: standard deviation.

Following IM administration, the $\mathrm{AUC}_{\text {milk }} / \mathrm{AUC}_{\text {serum }}$ and $C_{\text {max-milk }} / C_{\text {max-serum }}$ ratios of tylosin were calculated as $5.01 \pm$ 0.72 and $3.61 \pm 0.69$, respectively. These results were found to comply with those reported by Ziv and Sulman [1] in cattle and sheep (the $\mathrm{AUC}_{\text {milk }} / \mathrm{AUC}_{\text {serum }}$ ratio was reported as 3.5 and the $C_{\text {max-milk }} / C_{\text {max-serum }}$ ratio was reported as 2.5 ), but they were observed to be lower than those reported by $\mathrm{Al}$ Wabel [25] (the $\mathrm{AUC}_{\text {milk }} / \mathrm{AUC}_{\text {serum }}$ ratio was reported as 29.5 and the $C_{\text {max-milk }} / C_{\text {max-serum }}$ ratio was reported as 11.8).

Following SC administration, the $\mathrm{AUC}_{\text {milk }} / \mathrm{AUC}_{\text {serum }}$ and $C_{\text {max-milk }} / C_{\text {max-serum }}$ ratios of tilmicosin were calculated as $23.91 \pm 6.38$ and $20.16 \pm 1.13$, respectively. In a previous study carried out in goats [17], the $\mathrm{AUC}_{\text {milk }} / \mathrm{AUC}_{\text {serum }}$ ratio was reported as $12.0 \pm 0.17$ and the $C_{\text {max-milk }} / C_{\text {max-serum }}$ ratio was reported as $7.33 \pm 0.13$.

In the present study, following IM administration, the $C_{\text {max }}, t_{\text {max }}$, and $t_{1 / 2 \beta}$ values of tylosin in milk were determined as $4.55 \pm 0.23 \mu \mathrm{g} / \mathrm{mL}, 4 \mathrm{~h}$, and $26.36 \pm 5.55 \mathrm{~h}$, respectively (Table 1). In parallel with the maximum milk concentrations determined for tylosin in the present study, previous research demonstrated the maximum milk concentrations of tylosin as $6.22 \mu \mathrm{g} / \mathrm{mL}$ in cattle, $6.68-7.41 \mu \mathrm{g} / \mathrm{mL}$ in sheep, and $6.9 \mu \mathrm{g} / \mathrm{mL}$ in goats; and the time required to reach these concentrations as $6 \mathrm{hrs}, 7-4.5 \mathrm{~h}$, and $6 \mathrm{~h}$ in the same animal species, respectively $[1,20,25]$.

In the present study, following SC administration, the $C_{\text {max }}, t_{\max }$, and $t_{1 / 2 \beta}$ values of tilmicosin in milk were ascertained as $20.16 \pm 1.13 \mu \mathrm{g} / \mathrm{mL}, 8 \mathrm{~h}$, and $43.02 \pm 5.18 \mathrm{~h}$, respectively (Table 1). These findings were observed to display similarity to those reported in a previous study [17]. The findings obtained in the present study demonstrated that, shortly after being administered, tylosin and tilmicosin reached high concentrations in the milk and were eliminated from the body slowly.

The pharmacokinetic parameters determined for tylosin and tilmicosin in the present study showed that these drugs remain in milk and the body tissues for a long time period. When administered at the treatment dose $(10 \mathrm{mg} / \mathrm{kg}$ bw $)$ by IM route, the withdrawal period of tylosin in milk is 8 milkings and the MRL established for tylosin in milk is $50 \mu \mathrm{g} / \mathrm{kg}$ $[27,28]$. In the present study, tylosin was administered to cattle by IM route and at a dose of $17.5 \mathrm{mg} / \mathrm{kg}$ bw. The mean tylosin concentration determined in the samples taken at $96 \mathrm{~h}$ after administration $(0.20 \pm 0.09 \mu \mathrm{g} / \mathrm{mL})$ was found to be above the MRL. In view of the half-life of tylosin in milk $(26.36 \pm 5.55 \mathrm{~h})$, the withdrawal period established for milk was considered to be inadequate in ensuring the elimination of the drug.

The use of tilmicosin in lactating dairy cattle is prohibited. However, owing to a long retention period in the mammary glands and a long elimination period from the body having been determined for the SC administration of the drug, this antibiotic is known to be used illegally for the treatment of mastitis [17]. The EMEA has reported the encounter of such illegal use of tilmicosin in Europe and has also drawn attention to the lack of control of these cases [29]. The MRL in milk established for the administration of the treatment dose of tilmicosin $(10 \mathrm{mg} / \mathrm{kg}$ bw) by SC route is $50 \mu \mathrm{g} / \mathrm{kg}$ $[27,30]$. The mean tilmicosin concentration determined in the milk samples taken at $120 \mathrm{~h}$ after administration $(0.91 \pm$ $0.07 \mu \mathrm{g} / \mathrm{mL}$ ) was found to be significantly above the MRL.

In conclusion, as it was determined that the administration of tylosin and tilmicosin (illegal use of the latter) to 
lactating cows requires a long withdrawal period to be applied for milk, the use of these antibiotics in dairy cattle should be carefully regulated in view of the risk of residues associated with their therapeutic administration.

\section{Conflict of Interests}

The authors declare that there is no conflict of interests regarding the publication of this paper.

\section{Acknowledgments}

This research was summarized from a Ph.D. thesis and was supported by the Scientific Research Projects Coordinatorship of Selcuk University, Konya, Turkey (Project no. 08202007) and the Food and Feed Research Department under the Directorate General for Agricultural Research and Policies of the Ministry of Food, Agriculture and Livestock of the Republic of Turkey (Project no. TAGEM/GY/09/03/01/ 163).

\section{References}

[1] G. Ziv and F. G. Sulman, "Serum and milk concentrations of spectinomycin and tylosin in cows and ewes," American Journal of Veterinary Research, vol. 34, no. 3, pp. 329-333, 1973.

[2] D. A. Gingerich, J. D. Baggot, and J. J. Kowalski, “Tylosin antimicrobial activity and pharmacokinetics in cows," The Canadian Veterinary Journal, vol. 18, no. 4, pp. 96-100, 1977.

[3] N. A. Botsoglou and D. J. Fletouris, Drug Residues in Foods: Pharmacology: Food Safety and Analysis, Marcel Dekker, New York, NY, USA, 2000.

[4] M. Debono, K. E. Willard, H. A. Kirst et al., "Synthesis and antimicrobial evaluation of 20-deoxo-20-(3,5-dimethylpiperidin-1-yl)desmycosin (tilmicosin, EL-870) and related cyclic amino derivatives," The Journal of Antibiotics, vol. 42, no. 8, pp. 1253-1267, 1989.

[5] G. Ziv, M. Shem-Tov, A. Glickman, M. Winkler, and A. Saran, "Tilmicosin antibacterial activity and pharmacokinetics in cows," Journal of Veterinary Pharmacology and Therapeutics, vol. 18, no. 5, pp. 340-345, 1995.

[6] D. W. Morck, J. K. Merrill, M. S. Gard, M. E. Olson, and P. N. Nation, "Treatment of experimentally induced pneumonic pasteurellosis of young calves with tilmicosin," Canadian Journal of Veterinary Research, vol. 61, no. 3, pp. 187-192, 1997.

[7] C. M. Stobba-Wiley and R. S. Readnour, "Determination of tilmicosin residues in cow and sheep milk by liquid chromatography," Journal of AOAC International, vol. 83, no. 3, pp. 555$562,2000$.

[8] C. Clark, M. Woodbury, P. Dowling, S. Ross, and J. O. Boison, "A preliminary investigation of the disposition of tilmicosin residues in elk tissues and serum," Journal of Veterinary Pharmacology and Therapeutics, vol. 27, no. 5, pp. 385-387, 2004.

[9] J. W. Moran, J. M. Turner, and M. R. Coleman, "Determination of tilmicosin in bovine and porcine liquid chromatography," Journal of AOAC International, vol. 80, no. 6, pp. 1183-1189, 1997.

[10] M. A. García-Mayor, R. M. Garcinuño, P. Fernández-Hernando, and J. S. Durand-Alegría, "Liquid chromatography-UV diodearray detection method for multi-residue determination of macrolide antibiotics in sheep's milk," Journal of Chromatography A, vol. 1122, no. 1-2, pp. 76-83, 2006.
[11] E. Dudrikova, S. Jozef, and N. Jozef, "Liquid chromatographic determination of tylosin in mastitic cows milk following therapy," Journal of AOAC International, vol. 82, no. 6, pp. 1303-1307, 1999.

[12] WinNonlin Professional Version 4.1, Pharsight Corporation, Scientific Consulting, Cary, NC, USA.

[13] K. Yamaoka, T. Nakagawa, and T. Uno, "Application of Akaike's information criterion (AIC) in the evaluation of linear pharmacokinetics equations," Journal of Pharmacokinetics and Biopharmaceutics, vol. 6, no. 2, pp. 165-175, 1978.

[14] G. Ziv and F. G. Sulman, "Binding of antibiotics to bovine and ovine serum," Antimicrobial Agents and Chemotherapy, vol. 2, no. 3, pp. 206-213, 1972.

[15] A. R. Saurit, M. Rubio, E. Baroni, M. San Andrés, S. Sánchez, and J. C. Boggio, "Some comparative aspects of the pharmacokinetics of tylosin in buffaloes and cattle," Veterinary Research Communications, vol. 26, no. 1, pp. 49-54, 2002.

[16] S. Modric, A. I. Webb, and H. Derendorf, "Pharmacokinetics and pharmacodynamics of tilmicosin in sheep and cattle," Journal of Veterinary Pharmacology and Therapeutics, vol. 21, no. 6, pp. 444-452, 1998.

[17] A. Ramadan, "Pharmacokinetics of tilmicosin in serum and milk of goats," Research in Veterinary Science, vol. 62, no. 1, pp. 48-50, 1997.

[18] J. D. Baggot and D. A. Gingerich, "Pharmacokinetic interpretation of erythromycin and tylosin activity in serum after intravenous administration of a single dose to cows," Research in Veterinary Science, vol. 21, no. 3, pp. 318-323, 1976.

[19] G. E. Burrows, P. B. Barto, B. Martin, and M. L. Tripp, "Comparative pharmacokinetics of antibiotics in newborn calves: chloramphenicol, lincomycin, and tylosin," American Journal of Veterinary Research, vol. 44, no. 6, pp. 1053-1057, 1983.

[20] M. Atef, S. A. H. Youssef, A. H. Atta, and A. A. El-Maaz, "Disposition of tylosin in goats," The British Veterinary Journal, vol. 147, no. 3, pp. 207-215, 1991.

[21] A. A. Taha, H. A. Elsheikh, A. E. Khalafalla, I. A. Osman, and A. S. Abdullah, "Disposition kinetics of tylosin administered intravenously and intramuscularly in desert sheep and Nubian goats," The Veterinary Journal, vol. 158, no. 3, pp. 210-215, 1999.

[22] A. Womble, S. Giguère, Y. V. S. N. Murthy, C. Cox, and E. Obare, "Pulmonary disposition of tilmicosin in foals and in vitro activity against Rhodococcus equi and other common equine bacterial pathogens," Journal of Veterinary Pharmacology and Therapeutics, vol. 29, no. 6, pp. 561-568, 2006.

[23] E. A. Abu-Basha, N. M. Idkaidek, and A. F. Al-Shunnaq, "Pharmacokinetics of tilmicosin (Provitil powder and pulmotil liquid AC) oral formulations in chickens," Veterinary Research Communications, vol. 31, no. 4, pp. 477-485, 2007.

[24] M. Kim, E. Gebru, Z. Chang et al., "Comparative pharmacokinetics of tylosin or florfenicol after a single intramuscular administration at two different doses of tylosin-florfenicol combination in pigs," The Journal of Veterinary Medical Science, vol. 70, no. 1, pp. 99-102, 2008.

[25] N. A. Al-Wabel, "The pharmacokinetics and milk residual behaviour of tylosin in lactating Najdi ewes," Iranian Journal of Veterinary Research, vol. 9, no. 2, pp. 138-143, 2008.

[26] O. Keleş, T. Bakirel, S. Şener, G. Baktir, G. Dağoǧlu, and O. Özkan, "Pharmacokinetics and tissue levels of tilmicosin in fowls," Turkish Journal of Veterinary and Animal Sciences, vol. 25, no. 4, pp. 629-634, 2001. 
[27] Resmi Gazete: 24739 sayılı, “Türk Gıda Kodeksi-Hayvansal Kökenli Gıdalarda Veteriner İlaçları Maksimum Kalıntı Limitleri Tebliği (2002/30)," 2002, (Turkish).

[28] "EMEA: Tylosin Summary Report (5)," Committee for Vererinary Medicinal Products, EMEAMRL/829/02-FINAL, 2002.

[29] EMEA, "Reflection paper on the use of third and fourth generation cephalosporins in food producing animals in the European Union: development of resistance and impact on human and animal health," Journal of Veterinary Pharmacology and Therapeutics, vol. 32, no. 6, pp. 515-533, 2009.

[30] "EMEA: tilmicosin summary report," Tech. Rep. EMEA/MRL/ 619/99-FINAL, Committee for Vererinary Medicinal Products, 1999. 

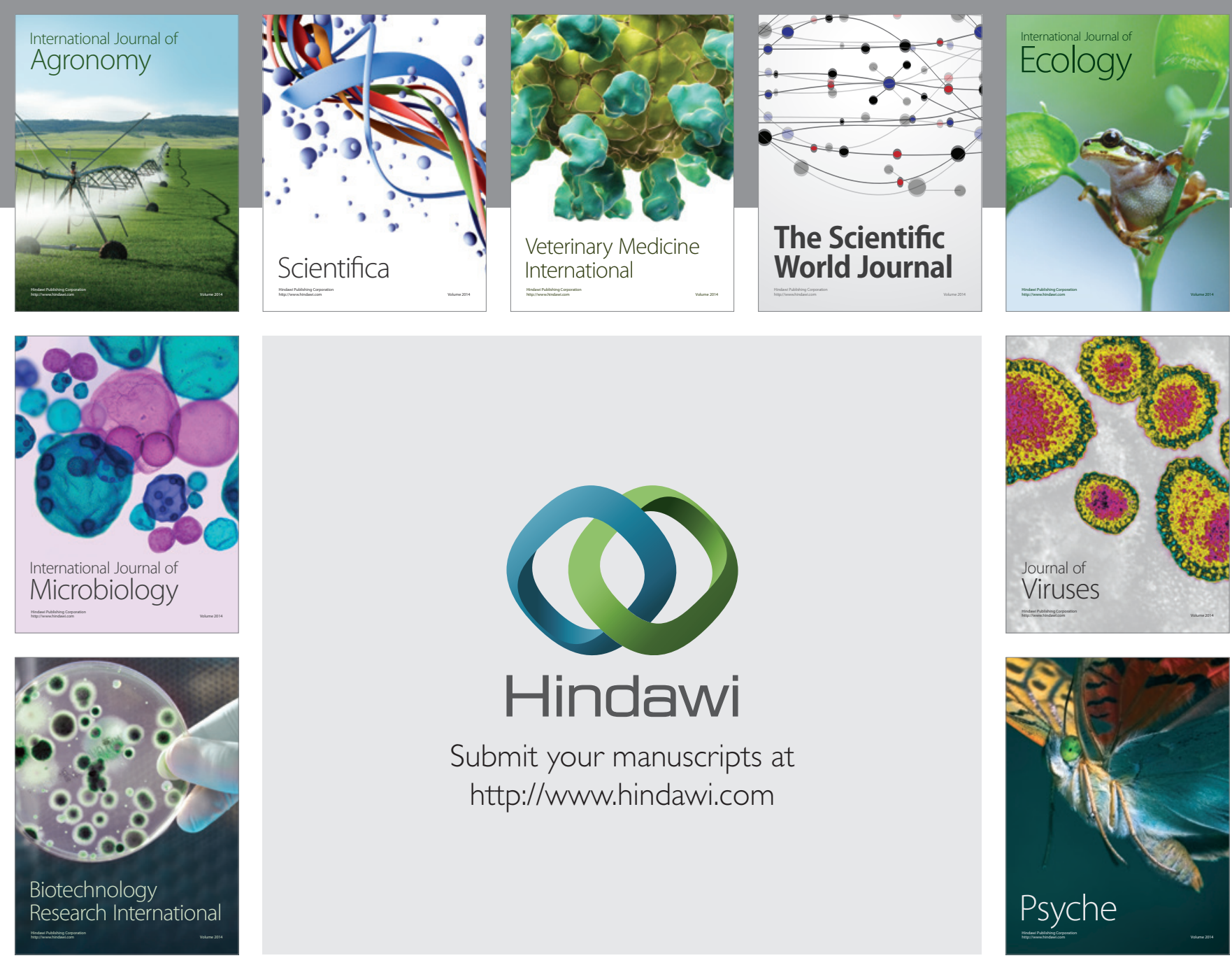

Submit your manuscripts at http://www.hindawi.com
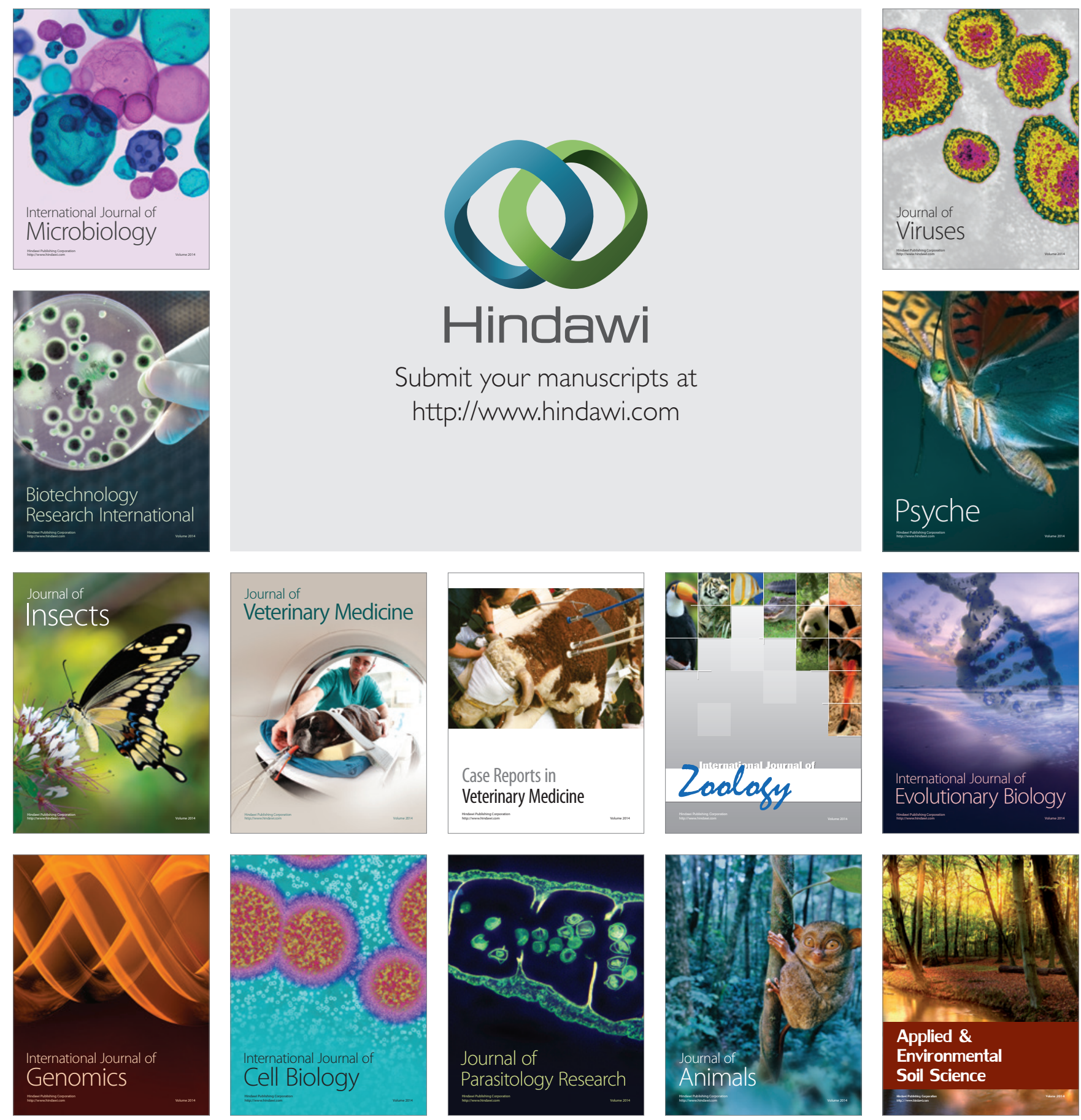